\title{
Developing nurse preceptor competency domain guide tool: A Delphi study
}

\author{
Mudhar Al Adawi ${ }^{1}$, Ibtisam Al Siyabi* ${ }^{* 1}$, Nasra Al Hashmi ${ }^{1}$, Fatma Mahmood AbdulRasool ${ }^{1}$, Asma Al Harrasi ${ }^{1}$, Khalid \\ Al Busaidi ${ }^{1}$, Warda Al Amri ${ }^{2}$ \\ ${ }^{1}$ Royal Hospital, Ministry of Health (MOH), Oman \\ ${ }^{2}$ Center for Studies and Research, Ministry of Health (MOH), Oman
}

Received: November 8, 2021

Accepted: December 12, $2021 \quad$ Online Published: December 23, 2021

DOI: $10.5430 /$ jnep.v12n5p33

URL: https://doi.org/10.5430/jnep.v12n5p33

\begin{abstract}
Background and objective: One of the strategies used to prepare novice nurses for their professional journeys in clinical practice is by implementing the preceptorship teaching and learning model. Competencies such as knowledge, experience, abilities, and attributes need to be measured to ensure the desired outcomes of the preceptorship are achieved and consistent. This study aimed to develop a nurse preceptor competency domain guide tool at a tertiary hospital in Oman.

Methods: Three-round Delphi iterative design with experts was used to develop the nurse preceptor competency domain guide tool. Following standard measures, eight expert opinions were combined until a group consensus was achieved. The level of consensus within the expert panel was defined as $\geq 75 \%$ scoring of items were selected as an essential required competency/item. Results: Eight experts from a main tertiary hospital were included in the panel. Five core competency domains and five subdomains were identified and considered to be relevant for nurse preceptors at the hospital with consensus levels varying from $75 \%$ to $100 \%$. A total of 83 descriptive items were identified for the competency guide tool.

Conclusions: This study found that the main core competency domains of the tool that nurse preceptors should acquire to be competent preceptors are inter-professional communication skills, appropriate teaching strategies, time management skills, building a learning atmosphere, and coaching critical thinking. This tool would improve nurse preceptors' performance and equip them with the required prerequisite competencies to professionally start their journey in clinical practices. Follow-up research on tool implementation is highly recommended to evaluate its effectiveness.
\end{abstract}

Key Words: Nurse preceptor, Novice nurse, Nurse intern, Clinical setting, Competency, Guiding tool, Preceptor skills

\section{INTRODUCTION}

Novice nurses (nurse interns) need continuous guidance and support as they start clinical practice. One of the common strategies to prepare the novice nurses for their professional journeys is by using the preceptorship teaching and learning model. ${ }^{[1]}$ It is acknowledged that the success of a preceptorship program depends greatly on the competence of the preceptors as well as their willingness to take responsibility for the preceptor's role. ${ }^{[2]}$ Yet, with the varied scope of supervisory preceptorship roles, maintaining precpetors' competencies becomes challenging.

Several studies reported that preceptors are inadequately prepared for their supervisory role due to being overwhelmed with clinical roles and other job-related responsibilities. ${ }^{[3-5]}$ As a result, the preceptor might become stressed to complete the program requirements including progress documentation. Furthermore, hospital management might have excessive expectations from the preceptor to provide successful education,

*Correspondence: Ibtisam Al Siyabi; Email: bisaa85@gmail.com; Address: Royal Hospital, Ministry of Health (MOH), Oman. 
socialization, and role modelling whereas the initial education on how to be effective preceptors is compromised. ${ }^{[5]}$ Therefore, the development of a nurse preceptor competence domain guide tool is crucial to offer support for the preceptors and to develop their skills and abilities to precept others. Bartlett et al. ${ }^{[6]}$ and Wray et al. ${ }^{[7]}$ reported that development and support given to preceptors may lead to improvements in retention and satisfaction of nurse interns.

According to Australia TPS, ${ }^{[8]}$ competencies include a combination of knowledge, experience, abilities and attributes. For a preceptorship program to be consistent, these competencies need to be clear, well-structured and regularly measured to ensure achievement of desired outcomes. ${ }^{[6]}$ Lee-Hsieh et al. ${ }^{[9]}$ created Clinical Teaching Behavior Inventory (CTBI) that contains certain domains. These competency domains are; 1) committing to teaching, 2) building a learning atmosphere, 3) using appropriate teaching strategies, 4) guiding inter-professional communication, 5) providing feedback and evaluation, and 6) showing concern and support. Based on the CTBI, this study aims to develop a nurse preceptor competency domain guide tool for a tertiary hospital using the Delphi method.

\section{Methodology}

\subsection{Study design}

The Delphi method is a well-grounded technique to establish consensus. It is characterized by multiple rounds with a panel of experts. The group responds to a questionnaire by scoring questionnaire items in terms of importance or the level of agreement. ${ }^{[10]}$ In this study, a three-round Delphi iterative design with experts was used to develop the preceptors' com- petency domain guide tool. Following standard measures, expert opinions were combined, summarized and shared with the panel in the next rounds and until group consensus was achieved. ${ }^{[10]}$

\subsection{Participants}

To develop the main core competencies of nurse preceptors, participation was sought from a panel of mixed senior expert preceptors with expectation that each participant will provide unique and rich information of value to achieve the objectives of this study. These experts fit the profile of being 'ideal' preceptors as they were previously rated as excellent preceptors by their preceptee.

Since there is no clear guidance on optimal sample size for the Delphi group, ${ }^{[10]}$ non-probability purposive sampling was used to recruit the panel of experts. The finalized panel consisted of eight participants who are treating as an identical group since they share the same "nursing" fundamentals. More information about the expert panel is available in Table 1.

\subsection{Questionnaire development}

Preceptors' competency domain guide tool was structured by the main author from literature. The criteria of preceptors based on the national internship nursing program were also used. An initial meeting with all preceptors was conducted during which the roles were developed and grouped under certain competencies. The tool consists of five domains, three subdomains, and 62 elements that describe each domain and sub-domain. This tool then was transferred to an online survey for distribution.

Table 1. Information about expert panel

\begin{tabular}{|l|l|l|l|}
\hline Expert Type & $\begin{array}{l}\text { Number of } \\
\text { Participants }\end{array}$ & Qualification & Experience Description \\
\hline Senior clinical educator & 1 & Post-graduate certification & Extensive experience in clinical education \\
\hline Nurse researcher & 1 & Master degrees in related disciplines & Extensive research background in nursing sciences \\
\hline Nurse manager & 1 & Master degree in a related discipline & Senior decision-making roles \\
\hline $\begin{array}{l}\text { Nursing human resource } \\
\text { staff }\end{array}$ & 2 & $\begin{array}{l}\text { Post graduates diploma in human } \\
\text { resource }\end{array}$ & $\begin{array}{l}\text { Planning and supervising national internship } \\
\text { program, as well as preceptorship workshops }\end{array}$ \\
\hline $\begin{array}{l}\text { Representative of training } \\
\text { and studies department }\end{array}$ & 1 & Master degree in medical education & $\begin{array}{l}\text { Managing training programs of preceptors and } \\
\text { preceptee }\end{array}$ \\
\hline
\end{tabular}

This study was conducted at a tertiary hospital from February 2020 till September 2020. The Delphi method was utilized in a three-round process. The first round aimed to rate the importance of a set of pre-determined domains, subdomains, and elements. Furthermore, it aimed to add other domains, sub-domains, or descriptions based on literature and discussions. A link to the online format of the preceptor competency domains tool was shared with the expert panel. A five-point Likert scale was used to rate the importance of each domain as it is proven that they are mutually exclusive and collectively exhaustive. ${ }^{[11]}$ The panel rated the tool based on the importance of each element of the competence guide using a 1-5 scale, where 5 indicates very important, 4 important, 3 neutral (so-so), 2 less important, and 1 not important. The panel was also requested to add any other domains they perceive important with their statements. 
The importance scale was placed below each domain and sub-domain to encourage the expert panel to consider each statement individually. ${ }^{[12]}$ There is no universal literature agreement on the acceptable level of consensus. According to du Plessis, ${ }^{[13]}$ the consensus depends on the aim of the research, the sample size and resources. In this study, the researchers decided that statements with importance level of $75 \%$ and above will be considered forward for the second round.

In the second round, more focus was on the newly added statements based on the level of importance and the flow of each domain and statement. The results of the first round (those with $75 \%$ and above agreement of importance) and the added statements were shared with the panel. The panel was asked to rate the newly added domains using a 1-5 scale based on their importance and consider the sequence of each domain with its descriptions. An online link was shared with them to provide their feedback. However, this round did not provide the participants with the option of adding their comments or insights.

Testing the feasibility, readability, and revision of the content was done in the third and final round. An online link was shared with the panel to provide their feedback on the feasibility of each domain. This was done using three nominal measures; yes, no, or not sure. The panel was also asked to suggest alternative phrases to replace the domains and subdomains or their descriptions. Feedback on this round was communicated with the panel for confirmation.

\subsection{Data Analysis}

Descriptive statistics such as frequencies and percentages were used to summarize the results of Delphi iterative rounds. The level of consensus within the expert panel was defined as $\geq 75 \%$ and above. ${ }^{[14]}$ Qualitative analysis of the third round was transformed into themes. More specifically, themes were transformed by adding the description of each author independently. Then they were combined and translated into competency domains, sub- domains and item descriptions. Finally, these themes were sent back to the panel for overall agreement.

\subsection{Ethical consideration}

Ethical approval was granted by the Scientific Research Committee at the tertiary hospital in Oman. The approval number is SRC\#3/2020. All participants were provided verbal information about the research aim, and details of requirements. Participants were assured of complete confidentiality and anonymity. All the panel members have sufficient knowledge about the Delphi method, and therefore no training was required.

\section{Results}

Round 1: Analysis of the first round rendered 82 items from 78 of the initial tool. One added core competency domain is time management skill with 10 descriptive items. However, 4 descriptive items were deleted since they scored below $75 \%$ consensus of agreement. A total of five core competency domains and five sub-competencies domains were identified for the first round.

Round 2: The added core competency domain from the first round received $75 \%$ agreement. In addition, eight descriptive items for the added core competency domain reached a consensus of more than $75 \%$. However, two descriptive items received consensus below $75 \%$ and therefore were deleted. Six descriptive items were added under different competency domains. Five of them reached more than $75 \%$ of agreement on their importance; and consequently, one descriptive item was deleted. The panel reached an agreement on the sequence of each competency domain, sub-competency domains and statements.

Round 3: the expert panel rated the feasibility of each competency domain and their descriptive items. The panel also suggested alternative phrases to make them clear for the preceptors. Table 2 displays the suggested sequence and level of importance of each descriptive item. Five main competency domains and five subdomains were identified as relevant for nurse preceptors with consensus levels varying from $75 \%$ to $100 \%$. A total of 83 description items were identified for the competency domain guide tool.

In overall, guiding novice nurses to develop interprofessional communication skills had the first sequence according to the panel with a $100 \%$ rate of importance, feasibility and applicability. Despite considering coaching critical thinking as $100 \%$ important, it had the fifth sequence of domains according to the panel and a $75 \%$ feasibility/applicability rate.

\section{Discussion}

To our knowledge, this is the first study that identifies the core competency domains of nurse preceptors in a clinical setting and discusses steps/activities of achieving them. Previous studies have recognized preceptors' roles and responsibilities with nursing students. ${ }^{[15]}$ This study revealed five major domains in the competency domain guide tool required by the nurse preceptor. These domains are; guiding novice nurses to develop inter-professional communication skills, appropriate teaching strategies, time management skills, building a learning atmosphere, and coaching critical thinking. The finalized version of the nurse preceptor competency domain guide tool is shown in Figure 1. 
Table 2. The suggested sequence and level of importance of each descriptive item

\begin{tabular}{|l|l|l|l|l|l|}
\hline \multirow{5}{*}{ Domain/sub-domain } & $\begin{array}{l}\text { Rate of } \\
\text { importance }\end{array}$ & $\begin{array}{l}\text { The sequence of the } \\
\text { domain according to } \\
\text { the panel }\end{array}$ & $\begin{array}{l}\text { Feasibility/ } \\
\text { applicability } \\
\text { \% }\end{array}$ & $\begin{array}{l}\text { Comments of the } \\
\text { phrases }\end{array}$ \\
\hline \multirow{5}{*}{ Domains } & $\begin{array}{l}\text { Guide novice nurses to develop } \\
\text { interprofessional } \\
\text { Communication skills }\end{array}$ & $100 \%$ & First & $100 \%$ & $\begin{array}{l}\text { Suggested change } \\
\text { of the phrase }\end{array}$ \\
\cline { 2 - 6 } & Appropriate teaching strategies & $100 \%$ & Second & $75 \%$ & Statement is clear \\
\cline { 2 - 6 } & Time Management Skills & $75 \%$ & Third & $87.5 \%$ & Statement is clear \\
\cline { 2 - 6 } & Build a learning atmosphere & $87.5 \%$ & Fourth & $75 \%$ & Statement is clear \\
\cline { 2 - 6 } & Coaching critical thinking & $100 \%$ & Fifth & $75 \%$ & Statement is clear \\
\hline \multirow{5}{*}{ Sub-domains } & $\begin{array}{l}\text { Novice nurse performance } \\
\text { assessment technique* }\end{array}$ & $100 \%$ & Second & $100 \%$ & Statement is clear \\
\cline { 2 - 6 } & $\begin{array}{l}\text { Evaluation \& feedback of the } \\
\text { novice nurse }\end{array}$ & $100 \%$ & Fifth & $100 \%$ & Statement is clear \\
\cline { 2 - 6 } & $\begin{array}{l}\text { Setting goals and individual } \\
\text { learning needs }\end{array}$ & $100 \%$ & First & $100 \%$ & Statement is clear \\
\cline { 2 - 6 } & Teaching strategies & $75 \%$ & Third & $75 \%$ & Statement is clear \\
\cline { 2 - 6 } & $\begin{array}{l}\text { Demonstration of organized } \\
\text { knowledge }\end{array}$ & $75 \%$ & Fourth & $75 \%$ & Statement is clear \\
\hline
\end{tabular}

*Initially it was domain three and then suggested to be merged

\begin{tabular}{|c|}
\hline Domain \\
\hline Subdomain \\
\hline $\begin{array}{c}\text { Steps/activities to help achieve the } \\
\text { domain/subdomain }\end{array}$ \\
\hline
\end{tabular}

\section{Support novice nurse to develop inter-professional} communication skills

1.0.1 Promote teamwork of the nurse intern with others to increase her his experience

Assist the nurse intern in socialization by involving her him in all unit activities

1.0.4 Start communicating with build her his interpersonal relationship frst and end each first and end each communication with positive comments
Be an influencer by sharing the nurse intern your personal Keep your emotion in control during conflicts, remain calm and alert (practice emotional intelligence concept)

1.0.7 Always take notes when you are informal communication during communication

doring commonicaton Always summarize your talk at the end of conversations environment

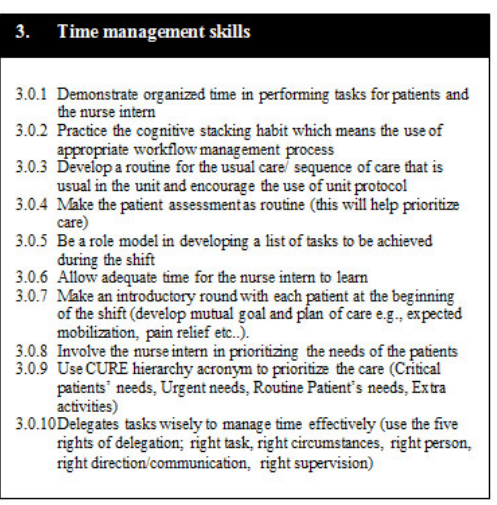

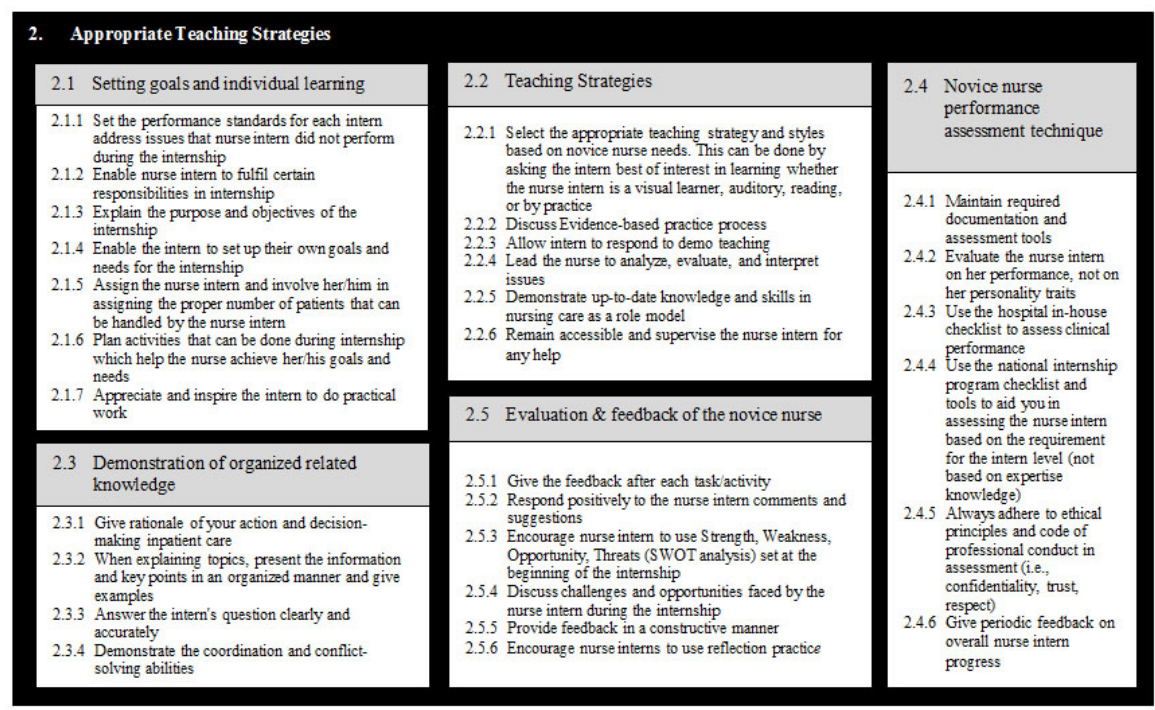

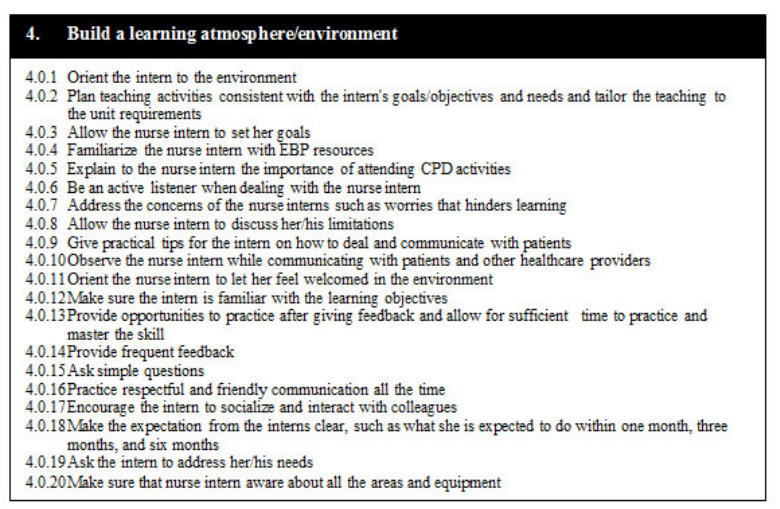

Figure 1. Nurse preceptor competency domain guide tool 


\subsection{Effective interprofessional communication}

Under this domain, preceptors need to assist nurse interns to effectively communicate with other healthcare providers, patients and relatives. As recommended by the study panel, interprofessional communication can be promoted by implementing and promoting team working skills. Teamwork enriches the nurse intern experience in working with others. This is a critical element as the nurse is required to work with a multidisciplinary team to meet patients' needs and provide optimum care. Teamwork is proven to improve the quality of care and enhance patient safety as supported by Omer et al. ${ }^{[15]}$ Moreover, based on the organization goal related to patient safety, the panel emphasized that teamwork is a crucial skill for the preceptee to acquire throughout the internship program. It also helps to maximize individuals' strengths and overcome their weaknesses to achieve the team common goal.

To be effective in a clinical practice, nurse interns need to build interpersonal relationship skills. The panel agreed that the preceptor, as well as the preceptee, need to work together on achieving good interpersonal relationship skills. As supported by Hong et al. ${ }^{[16]}$ and Lapeña-Moñux, ${ }^{[17]}$ this strategy is essential for the nurse interns to feel content in the work environment and be more confident and satisfied in their work. It is also vital that preceptors provide the nurse inters with well-structured and positive feedback before and at the end of each communication. This strategy will help them to learn faster and effectively contribute to their teams. Omer et al. ${ }^{[15]}$ reported that constructive feedback encourages the nurse interns to improve their knowledge.

The study panel suggested other strategies that preceptors need to follow to improve interprofessional communication of nurse interns. These include focusing on the preceptors emotional intelligence and preceptor's nonverbal communication such as body language and eye contact. Bambaeeroo and Shokrpour ${ }^{[18]}$ emphasized that nonverbal communication can cause a positive effect on the teaching and learning process. Therefore, preceptors are required to give a special attention to these skills. Moreover, it is also important that the preceptors summarize their discussions with the nurse inters. This will ensure having full understanding of the discussion and avoid missing important information. The expert panel also agreed that the preceptors need to influence the nurse interns by sharing their clinical scenarios, such as nursing experience stories. These steps allow the preceptors to establish a good relationship with the nurse inters and show empathy.

\subsection{Appropriate teaching strategies}

This domain describes the strategies that preceptors should use to help novice nurses learn the required skills, knowledge, and behaviour. The expert panel agreed that effective teaching strategies are essential building preceptors' competencies and identified five subdomains to achieve this. First and foremost, the preceptors need to work closely with preceptees to properly plan for preceptorships by setting achievable goals and individual learning objectives. Special focus should be given to the appropriate number of patients that the preceptees can handle so that they provide safe care for the patient. ${ }^{[19]}$

Secondly, preceptors should use innovative and attractive teaching strategies to stimulate the learning process. Phillips and Vinten ${ }^{[20]}$ emphasized that preceptors should become facilitators of learning rather than lecturers. Due to the dynamic and challenging nature of the clinical setting, the study panel suggested to use practical oriented teaching strategies. These include questioning, role-playing, simulation, case studies, Problem Based Learning (PBL) and debating. These methods can help in improving the nurse intern knowledge, skills, and attitudes. ${ }^{[20]}$ During preceptorships, the preceptors should also give special attention to their demonstration of related knowledge and practice. In specific, they should give rationale of their actions, present information in organized manners, provide clear and accurate responses to preceptee's questions, and have conflict solving abilities.

The study found that preceptors need to use performance assessment techniques. Based on the national internship program requirements, the study panel concluded that the preceptors are strongly required to adhere to the hospital competency checklist. The panel also agreed that the nursing code of conduct in assessing the nursing ethical principles is a core requirement. Moreover, the preceptors should provide preceptees with periodic evaluation and feedback. Hsu et al. ${ }^{[21]}$ emphasizes that providing feedback based on tasks and activities helps the novice nurses to focus on specific task achievement and stimulate a culture of continuous improvement. As it was evident that chance of making error is high during preceptorships, the study panel strictly emphasized that preceptors need to be available and accessible to supervise the preceptees when needed.

\subsection{Time management skills}

Time management skills are critical job requirements especially in clinical settings. Unsurprisingly, it is a domain in the competency guide tool. To be effective in time management, it is recommended that preceptors teach novice nurses the cognitive staking process in a clinical setting. ${ }^{[22]}$ The research panel agreed that the preceptors need to develop pre- 
ceptee's skills in conducting daily routine nursing tasks. The panel also recommended that the preceptors should encourage the novice interns to effectively prioritize their nursing tasks through using, for example, CURE (Critical, Urgent, Routine and Extra) hierarchy. Carvalho et al. ${ }^{[23]}$ emphasized that prioritizing ability and mindfulness are skills of time management. This, therefore, will safeguard the transition of the novice nurse from being a competent qualified nurse to a proficient nurse.

\subsection{Building a learning atmosphere}

Competencies of novice nurses is progressively developed by practicing nursing skills in a healthy and supportive learning atmosphere. ${ }^{[2]}$ The study found that the preceptors' support to preceptees is as a significant factor that influences the learning process. Subsequently, a healthy atmosphere may lead to retention of the novice nurses in the service. Aboshaiqah and Qasim ${ }^{[25]}$ stated that the approachable attitude and trustworthiness of the preceptors are essential qualities for creating a positive learning atmosphere. From this perspective, the expert panel encouraged the preceptors to orient the novice nurses to the work environment, familiarize them with available resources, be an active listener, and provide frequent feedback. Omer et al. ${ }^{[15]}$ emphasized that the use of constructive feedback helps the novice nurses to build their competencies. These elements of building a positive relationship are critical elements for building a learning atmosphere.

\subsection{Coaching critical thinking}

The last domain in the proposed competency guide tool is coaching critical thinking. This domain emphasizes the need to educate novice nurses on how to think critically and rely on critical thinking in making decisions. The study found that preceptors should use real-life scenarios on critical thinking processes using different models such as Gibb's cycle and reflective judgment in analyzing different scenarios. The panel used these two strategies in promoting critical thinking since it is one of the requirements of the National Internship Program (NIP). This program was designed by the Ministry of Health and used by institutions nationally. The program requires novice nurses to write Gibb's reflection and reflective judgment at least once throughout the internship period. The panel agreed that reflective thinking will encourage the novice nurses to use questioning strategy to enhance the thinking process. Schuelke et al., ${ }^{[26]}$ Cui et al. ${ }^{[27]}$ and Forneris et al. ${ }^{[28]}$ argued that concept mapping and reflective thinking empower the nurses to be active in their learning process, and allow them to justify the rationale behind actions. The panel also recommended using evidence- based practice, thinking loud approach, and/or building on past learning experiences to drive critical thinking. The use of evidence-based practice in nursing can enhance critical thinking and promote questioning habit during clinical practice. ${ }^{[27]}$ Wu et al. ${ }^{[29]}$ emphasized that thinking out loud and dialogue strategy helps the nurse to be more intentional and reflective.

Task prioritization is crucial in clinical settings. This study there stressed the urgent need that preceptors not just be a role model in task prioritization according to patient needs, but also to coach novice nurses to effective doing it. This can be done by giving directions on accomplishing important patient care, routine tasks, and procedures. ${ }^{[28]}$

Clinical situations are continuously changing, therefore; it is important to enhance novices' problem-solving techniques and boost their confidence. This can be achieved through transformational abilities, preceptors' teaching competency, role modelling, and highlighted clinical competencies. ${ }^{[29]}$

\section{Conclusion}

This study discussed the nurse preceptor competency domain guide tool. The study suggests that this tool should contain five main core competency domains that nurse preceptors should acquire to be competent preceptors. These domains were identified based on institution requirements as well as National Internship Program requirements. These competency domains are; 1) guiding novice nurses to develop interprofessional communication skills, 2) appropriate teaching strategies, 3) time management skills, 4) building a learning atmosphere, and 5) coaching critical thinking. Under each of these domains, the study panel of experts identified certain tasks/activities and strategies that nurse preceptors could use to facilitate their role. It is expected that this tool would assist preceptors during preceptorship programs to equip novice nurses with the required prerequisite competencies to professionally start their journey in clinical practices. This unique tool adds to the existing knowledge about the preceptor roles in clinical education. The tool can guide the preceptors on the essential skills while supervising novice nurses. Moreover, any new preceptor could find this tool as an easy reference to facilitate their role requirements. In overall, this tool can be used as a guide in structuring preceptorship workshops.

However, this study is limited by the sample size and sampling design which limit the generalization of the findings. Further studies are recommended to test the validity and feasibility of the tool in different institutions with larger sample size. 


\section{ACKnOWLEDGements}

The authors would like to acknowledge the Royal Hospital administration for the support provided to conduct the study.

\section{CONFLICTS OF INTEREST Disclosure}

The authors declare that they have no competing interests.

\section{REFERENCES}

[1] Hardie P, Darley A, Redmond C, et al. Interpersonal and communication skills development in nursing preceptorship education and training programmes: a scoping review protocol. HRB Open Res. 2021; 4: 9. https://doi.org/10.12688/hrbopenres.13201.1

[2] Washington GT. The theory of interpersonal relations applied to the preceptor- New graduate relationship. J Nurses Staff Dev. 2013; 29(1): 24-9. PMid:23486153 https://doi.org/10.1097/NND. Ob013e31827d0a8a

[3] Carlson E, Bengtsson M. Perceptions of preceptorship in clinical practice after completion of a continuous professional development course- a qualitative study Part II. BMC Nurs [Internet]. 2015; 14(1): 1-7. PMid:26236155 https://doi.org/10.1186/s12912-015 $-0092-8$

[4] Ford K, Courtney-Pratt H, Fitzgerald M. The development and evaluation of a preceptorship program using a practice development. Aust J Adv Nurs. 2013; 30(3): 5-13.

[5] Sandau KE, Cheng LG, Pan Z, et al. Effect of a Preceptor Education Workshop: Part 1. Quantitative Results of a Hospital-Wide Study. J Contin Educ Nurs. 2011; 42(3): 117-26. PMid:21053793 https://doi.org/10.3928/00220124-20101101-01

[6] Bartlett AD, Um IS, Luca EJ, et al. Measuring and assessing the competencies of preceptors in health professions: A systematic scoping review. BMC Med Educ. 2020; 20(1): 1-9. PMid:32448239 https://doi.org/10.1186/s12909-020-02082-9

[7] Wray J, Gibson H, Barrett D, et al. Approaches used to enhance transition and retention for newly qualified nurses (NQNs): a rapid evidence assessment. Nurse Educ Today. 2020; 1-40.

[8] Australia TPS of. National Competency Standards Framework for Pharmacists in Australia [Internet]. Technical Report. 2010. 1-92 p. Available from: https://www.psa.org.au/download/stan dards/competency-standards-complete.pdf

[9] Lee-Hsieh J, O'Brien A, Liu CY, et al. The development and validation of the Clinical Teaching Behavior Inventory (CTBI-23): Nurse preceptors' and new graduate nurses' perceptions of precepting. Nurse Educ Today. 2016; 38: 107-14. PMid:26743525 https://doi.org/10.1016/j.nedt.2015.12.005

[10] Keeney S, Hasson F, McKenna HP. A critical review of the Delphi technique as a research methodology for nursing. Int J Nurs Stud. 2001; 38(2): 195-200. https://doi.org/10.1016/S0020-748 $9(00) 00044-4$

[11] Rattray J, Jones MC. Essential elements of questionnaire design and development. J Clin Nurs. 2007; 16(2): 234-43. PMid:17239058 https://doi.org/10.1111/j.1365-2702.2006.01573.x

[12] Endacott R, Clifford CM, Tripp JH. Can the needs of the critically ill child be identified using scenarios? Experiences of a modified Delphi study. J Adv Nurs. 1999; 30(3): 665-76. PMid:10499224 https://doi.org/10.1046/j.1365-2648.1999.01116.x

[13] du Plessis E, Human SP. REVIEW THE ART OF THE DELPHI TECHNIQUE: HIGHLIGHTING ITS SCIENTIFIC MERIT Dr Emmerentia du Plessis. Heal Sa Gesondheid. 2007; 12(4): 13-24. https://doi.org/10.4102/hsag.v12i4.268

Published by Sciedu Press
[14] Slade SC, Dionne CE, Underwood M, et al. Standardised method for reporting exercise programmes: Protocol for a modified Delphi study. BMJ Open. 2014; 4(12): 1-5. PMid:25550297 https: //doi.org/10.1136/bmjopen-2014-006682

[15] Omer TA, Suliman WA, Moola S. Roles and responsibilities of nurse preceptors: Perception of preceptors and preceptees. Nurse Educ Pract [Internet]. 2016; 16(1): 54-9. PMid:26255079 https : //doi.org/10.1016/j.nepr.2015.07.005

[16] Hong KJ, Yoon HJ. Effect of nurses' preceptorship experience in educating new graduate nurses and preceptor training courses on clinical teaching behavior. Int J Environ Res Public Health. 2021; 18(3): 1-12. PMid:33499327 https://doi.org/10.3390/ijerph18030975

[17] Lapeña-Moñux YR, Cibanal-Juan L, Pedraz-Marcos A, et al. Interpersonal relationships among hospital nurses and the use of communication skills TT - Las relaciones interpersonales de los enfermeros en asistencia hospitalaria y el uso de habilidades comunicativas As relações interpessoais dos enfermeiros na assi. Texto Context - Enferm. 2014; 23(3): 555-62. https ://doi .org/10.1590/0104-0 7072014002010013

[18] Bambaeeroo F, Shokrpour N. The impact of the teachers' non-verbal communication on success in teaching. J Adv Med Educ Prof [Internet]. 2017; 5(2): 51-9.

[19] Agency for Healthcare Research and Quality. Nursing and Patient Safety I PSNet [Internet]. PSNet. 2020. p. 1-4.

[20] Phillips JM, Vinten SA. Why clinical nurse educators adopt innovative teaching strategies: A pilot study. Nurs Educ Perspect. 2010; 31(4): 226-9.

[21] Hsu LL, Hsieh SI, Chiu HW, et al. Clinical teaching competence inventory for nursing preceptors: Instrument development and testing. Contemp Nurse. 2014; 46(2): 214-24. PMid:24787255 https : //doi.org/10.5172/conu.2014.46.2.214

[22] Kohtz C, Gowda C, Guede P. Cognitive stacking: Strategies for the busy RN. Nursing (Lond). 2017; 47(1): 18-20. PMid:28027129 ht tps://doi.org/10.1097/01. NURSE.0000510758.31326.92

[23] Carvalho DPSRP, Azevedo IC, Cruz GKP, et al. Strategies used for the promotion of critical thinking in nursing undergraduate education: A systematic review. Nurse Educ Today. 2017; 57(July): 103-7. PMid:28783526 https://doi.org/10.1016/j.nedt.2017.07 .010

[24] Dunn SV, Hansford B. Undergraduate nursing students' perceptions of their clinical learning environment. J Adv Nurs. 1997; 25(6): 1299306. PMid:9181430 https://doi .org/10.1046/j.1365-2648. 1997.19970251299.x

[25] Aboshaiqah A, Qasim A. Nursing interns' perception of clinical competence upon completion of preceptorship experience in Saudi Arabia. Nurse Educ Today. 2018; 68(November 2016): 53-60. PMid:29886285 https://doi.org/10.1016/j.nedt.2018.05 .021

[26] Schuelke S, Barnason S. Interventions used by nurse preceptors to develop critical thinking of new graduate nurses: A systematic review. J Nurses Prof Dev. 2015; 31(1): E1-7. PMid:28059996 https://doi.org/10.1097/NND.0000000000000318 
[27] Cui C, Li Y, Geng D, et al. The effectiveness of evidence-based nursing on development of nursing students' critical thinking: A meta-analysis. Vol. 65, Nurse Education Today. 2018. p. 46-53. PMid:29525486 https://doi.org/10.1016/j.nedt.2018.02 .036

[28] Forneris SG, Peden-Mcalpine C. Creating context for critical thinking in practice: The role of the preceptor. J Adv Nurs. 2009; 65(8): 1715-
24. PMid:19602012 https://doi.org/10.1111/j.1365-2648. 2009.05031. $\mathrm{x}$

[29] Wu XV, Chi Y, Chan YS, et al. A web-based clinical pedagogy program to enhance registered nurse preceptors' teaching competencies - An innovative process of development and pilot program evaluation. Nurse Educ Today. 2020; 84: 104215. PMid:31683138 https://doi.org/10.1016/j.nedt.2019.104215 